Contribution from the Institut für Anorganische Chemie, Universität Regensburg, Universitätsstrasse 31, W-8400 Regensburg, Germany, and Department of Chemistry, University of California, Santa Barbara, California 93106

\title{
Photophysical Properties of Hexanuclear Copper(I) and Silver(I) Clusters
}

\author{
F. Sabin ${ }^{\dagger}$ C. K. Ryu, ${ }^{\ddagger}$ P. C. Ford, ${ }^{*}{ }^{\ddagger}$ and A. Vogler ${ }^{*} \dagger$ \\ Received October 25, 1991
}

\begin{abstract}
The spectroscopic properties, including emission spectra and lifetimes, absorption and diffuse reflectance spectra and excitation spectra, of the hexanuclear copper(I) and silver(I) clusters $\mathrm{Cu}_{6}(\mathrm{mtc})_{6}(1), \mathrm{Ag}_{6}(\mathrm{mtc})(2)$, and $\mathrm{Ag}_{6}(\mathrm{dtc})_{6}(3)$ (mtc $=\mathrm{di}-n$ propylmonothiocarbamate, dtc $=$ di- $n$-propyldithiocarbamate) are reported. At room temperature 1 exhibits a strong single emission (e.g., in toluene $\lambda_{\max }^{\mathrm{em}}=725 \mathrm{~nm}, \tau=1.0 \mu \mathrm{s}$ ), while at $77 \mathrm{~K}$ each of these is a bright emitter (spectral properties: 1 in toluene, $\lambda_{\max }^{\mathrm{em}}=762 \mathrm{~nm}, \tau=20 \mu \mathrm{s} ; 2$ in toluene, $\lambda_{\max }^{\mathrm{em}}=607 \mathrm{~nm}, \tau=131 \mu \mathrm{s} ; 3$ in toluene, $\lambda_{\max }^{\mathrm{em}}=550 \mathrm{~nm}, \tau=21 \mu \mathrm{s}$ ). In analogy to previous assignments in tetranuclear $\mathrm{Cu}(\mathrm{I})$ clusters, the emission bands in the octahedral $\left(\mathrm{M}^{1}\right)_{6}$ clusters are assigned to spin-forbidden transitions from triplet excited states which are mixed $d \rightarrow s$ and LMCT (ligand to metal charge transfer) in character modified by metal-metal interactions.
\end{abstract}

\section{Introduction}

During recent years there has been considerable interest in the photophysical properties of polynuclear $\mathrm{d}^{10}$ metal complexes, ${ }^{1}$ including those of copper(I), ${ }^{2-4}$ silver(I),,$^{5,6}$ and gold(I).$^{7,8}$ One issue of special interest is the extent of metal-metal interaction in the ground and relevant excited states. ${ }^{9-12}$ Although numerous studies have been concerned with the photophysical properties of polynuclear $\mathrm{Cu}(\mathrm{I})$ and $\mathrm{Au}(\mathrm{I})$ complexes, polynuclear complexes of the homologous $\mathrm{Ag}(\mathrm{I})$ metal center have received little attention, perhaps because of the sensitivity of silver compounds toward photodecomposition. In addition, previous quantitative studies of polynuclear $\mathrm{Cu}(\mathrm{I})^{2,3}$ complexes have been largely focused on compounds which contain a tetrahedral metal cluster. An extension of these investigations to hexanuclear octahedral metal clusters should be of considerable interest.

Described here are photophysical investigations of the hexameric copper(I) and silver(I) complexes $\mathrm{Ag}_{6}(\mathrm{mtc})_{6}(2),{ }^{13} \mathrm{Ag}_{6}(\mathrm{dtc})_{6}(3),{ }^{14}$ and $\mathrm{Cu}_{6}(\mathrm{mtc})_{6}(1)^{15}$ (mtc $=$ di- $n$-propylmonothiocarbamate, $(n$ $\left.\mathrm{C}_{3} \mathrm{H}_{7}\right){ }_{2} \mathrm{NC}(\mathrm{O}) \mathrm{S}^{-} ;$dtc $=$di- $n$-propyldithiocarbamate, $(n$ $\left.\mathrm{C}_{3} \mathrm{H}_{7}\right)_{2} \mathrm{NCS}_{2}^{-}$), each of which has a structure analogous to $\mathrm{A}$ shown in Figure 1.

\section{Experimental Section}

Materials. All chemicals used in syntheses were reagent grade. Emission, excitation and lifetime data were recorded under a dinitrogen atmosphere. Solvents for spectroscopic studies were redistilled before use

Compounds 1 and 2 were synthesized and purified according to published methods. ${ }^{15}$ Compound 3 was synthesized by Ákerström's method ${ }^{16}$ and purified by column chromatography (mobile phase toluene/diethyl ether (1:1); stationary phase Sigma No. A 9003 Chromatographic Alumina Neutral Type WN-3 activity grade I). Exposure to light during synthesis and purification of 2 and 3 was avoided.

Melting points and crystal lattice constants of 1 and 2 were in good correspondence with data published by Ákerström, ${ }^{16}$ Hesse, ${ }^{15}$ and Jennische ${ }^{13}$ (1 published, mp $180-183^{\circ} \mathrm{C}, a=13.425 \AA, b=19.357 \AA, c$ $=11.630 \AA, \alpha=\gamma=90.00^{\circ}, \beta=91.72^{\circ} ; 1$ experimental, $\mathrm{mp} 180-182$ ${ }^{\circ} \mathrm{C}, a=13.381 \AA, b=19.390 \AA, c=11.615 \AA, \alpha=\gamma=90.00^{\circ}, \beta=$ $90.21^{\circ} ; 2$ published, $\mathrm{mp} 133-134^{\circ} \mathrm{C}, a=13.313 \AA, b=19.904 \AA, c=$ $11.901 \AA, \alpha=\gamma=90.00^{\circ}, \beta=93.28^{\circ} ; 2$ experimental, mp $129-131^{\circ} \mathrm{C}$ $\operatorname{dec}, a=13.241 \AA, b=19.672 \AA, c=11.766 \AA, \alpha=\gamma=90.00^{\circ}, \beta=$ $\left.90.33^{\circ}\right)$. The melting point of $3\left(\mathrm{mp} 152-153^{\circ} \mathrm{C}\right.$ ) was in agreement with published data ${ }^{16}\left(\mathrm{mp} 154-155^{\circ} \mathrm{C}\right)$. The experimental powder pattern of 3 matched the pattern generated by published data. ${ }^{14}$ The elemental analyses of 1-3 were in good agreement with calculated data. Anal. Calcd for $1, \mathrm{C}_{42} \mathrm{H}_{84} \mathrm{~N}_{6} \mathrm{O}_{6} \mathrm{~S}_{6} \mathrm{Cu}_{6}$ : $\mathrm{C}, 37.57 ; \mathrm{H}, 6.31 ; \mathrm{N}, 6.26$. Found: $\mathrm{C}$, 37.61; $\mathrm{H}, 6.21 ; \mathrm{N}, 6.29$. Calcd for $2, \mathrm{C}_{42} \mathrm{H}_{84} \mathrm{~N}_{6} \mathrm{O}_{6} \mathrm{~S}_{6} \mathrm{Ag}_{6}$ : C, 31.36; $\mathrm{H}$, 5.26; N, 5.22. Found: C, 31.43; H, 5.23; N, 5.26. Calcd for 3 , $\mathrm{C}_{42} \mathrm{H}_{84} \mathrm{~N}_{6} \mathrm{~S}_{12} \mathrm{Ag}_{66}: \mathrm{C}, 29.59 ; \mathrm{H}, 4.97 ; \mathrm{N}, 4.93$. Found: $\mathrm{C}, 29.42 ; \mathrm{H}, 4.80$; $\mathrm{N}, 4.82$.

Solutions of 1 and 2 were thermally stable but underwent slow decomposition when irradiated with white light. Solid samples of 2 were sensitive to irradiation with a Nd/YAG laser $(355 \mathrm{~nm})$. Solutions and solid samples of 3 were highly sensitive to irradiation with white light or a Nd/YAG laser ( $355 \mathrm{~nm})$. Solutions of 3 were much less stable than

\footnotetext{
${ }^{\dagger}$ Universität Regensburg.

tUniversity of California.
}

those of 1 or 2. Pure 3 exhibited a green emission (about $550 \mathrm{~nm}$ ) when irradiated with UV light at $77 \mathrm{~K}$. The decomposed product exhibited a very broad orange to red emission (up to $700 \mathrm{~nm}$ ) under the same conditions.

Instrumentation. Absorption spectra of solutions were collected with a HP 8452 diode array UV/vis spectrophotometer in 1-cm quartz cells.

Diffuse reflectance (DR) spectra of solids were recorded on a Cary $14 \mathrm{UV} /$ vis spectrophotometer equipped with an integrating sphere and On-Line Instrument Systems (OLIS) computer control system in the laboratory of G. Stucky at UCSB. Solid $\mathrm{MgCO}_{3}$ was used as reference, and samples were diluted with $\mathrm{MgCO}_{3}$ ( 5-10\% sample by weight).

Emission spectra were collected with a Spex Fluorolog 2 spectrofluorimeter (150-W Xe lamp, two single monochromators, water-cooled Hamamatsu R928A photomultiplier (PMT) configured for photon counting) with a Spex Datamate II data station. Emission was passed through a Corning glass cutoff filter (3-72 or 3-71) prior to the PMT. Emission spectra were normalized but were not corrected for PMT response. Quartz or Pyrex tubes (diameter $5 \mathrm{~mm}$ ) sealed with septa or flame-sealed were used as sample cells. The range of solution concentrations used was $10^{-4}-10^{-5} \mathrm{M}$. Data at $77 \mathrm{~K}$ were recorded by cooling the sample with liquid nitrogen in a Pyrex Dewar flask.

Excitation spectra were collected with the Spex Fluorolog 2 system and were normalized and corrected for lamp intensity variation by the ratio method with Rhodamine $6 \mathrm{G}$ reference.

Lifetime data were collected with a Quanta Ray DCR-1A Q-switched $\mathrm{Nd} / \mathrm{YAG}$ pulsed laser (operating at $10 \mathrm{~Hz}$ ) as the excitation source. The power output at $355 \mathrm{~nm}$ was $40-50 \mathrm{~mJ} /$ pulse for samples of 1 and $<10$ $\mathrm{mJ} / \mathrm{pulse}$ for samples of 2 and 3. A HG-1 harmonic generator and a PHS-1 harmonic separator were used to isolate the desired third harmonic $(355 \mathrm{~nm})$. Specific wavelength dichroic mirrors mounted on beam steering towers were used to direct the excitation beam and to ensure laser-line quality at the sample. The sample emission was monitored at a right angle to the excitation source. The sample emission was filtered with appropriate filters (Schott plastic filter KV-388 and Corning glass cutoff filters 3-72 and 3-69, Schott glass filters LP 40 and LP 54) to reduce laser scatter prior to entering a Spex Model 1680 Doublemate grating monochromator blazed at $500 \mathrm{~nm}$. The emission intensity was monitored at selected wavelengths with an RCA 8852 fast-response PMT. The PMT output was terminated (50 $\Omega$ ) into a Tektronix 7912AD

(1) For review of $\mathrm{d}^{10}$ metal complexes see: Kutal, C. Coord. Chem. Rev. $1990,99,213-252$

(2) Vogler, A.; Kunkely, H. J. Am. Chem. Soc. 1986, 108, 7211-7212.

(3) Kyle, K. R.; Ryu, C. K.; Ford, P. C. J. Am. Chem. Soc. 1991, 113, 2954-2965 and references therein.

(4) Ryu, C. K.; Kyle, K. R.; Ford, P. C. Inorg. Chem. 1991, 30, 3982-3986.

(5) Stillmann, M. J.; Zelazowski, A. J.; Szymanski, J.; Gasyma, Z. Inorg. Chim. Acta 1989, 161, 275-279.

(6) Vogler, A.; Kunkely, H. Chem. Phys. Lett. 1989, 158, 74-76.

(7) Yam, V. W.-W.; Che, T.-F. L.; Che, C.-M. J. Chem. Soc., Dalton Trans. 1990, 3747-3752 and references therein.

(8) King, C.; Wang, J.-C.; Khan, M. N. I.; Fackler, J. P., Jr. Inorg. Chem. $1989,28,2145-2149$.

(9) Mehrotra, P. K.; Hoffman, R. Inorg. Chem. 1978, 17, 2187-2189.

(10) Jiang, Y.; Alvarez, S.; Hoffman, R. Inorg. Chem. 1985, 24, 749-757.

(11) Merz, K. M., Jr.; Hoffman, R. Inorg. Chem. 1988, 27, 2120-2127.

(12) Lee, S. W.; Trogler, W. C. Inorg. Chem. 1990, 29, 1659-1662.

(13) Jennische, P.; Hesse, R. Acta Chem. Scand. 1971, 25, 423-442

(14) Hesse, R.; Nilson, L. Acta Chem. Scand. 1969, 23, 825-845.

(15) Hesse, R.; Arva, U. Acta Chem. Scand. 1970, 24, 1355-1366.

(16) Ákerstöm. S. Ark. Kemi 1959, 14, 387-401; 1965, 24, 479-490. 


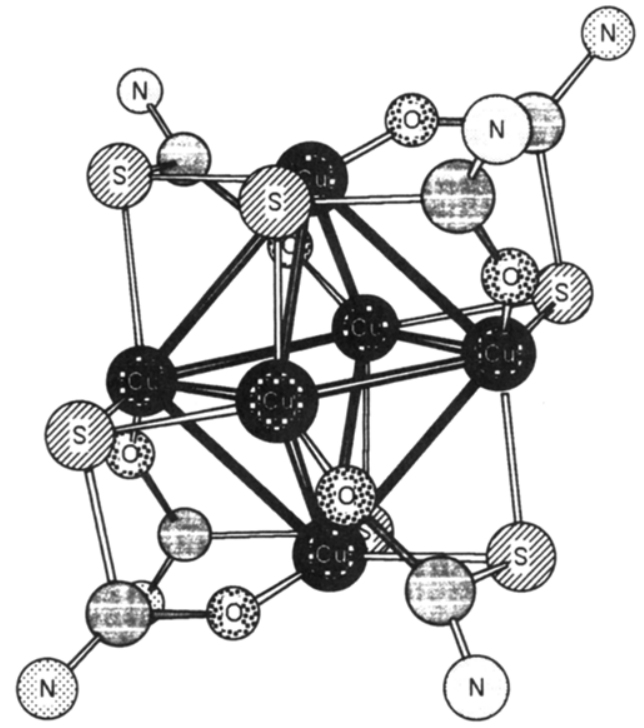

Figure 1. Qualitative illustration of the $\mathrm{Cu}_{6}(\mathrm{mtc})_{6}$ structure showing the edge bridging of the ligand sulfur atom, terminal coordination of the $\mathrm{mtc}^{-}$ oxygen, and the nearly octahedral arrangement of the six coppers.

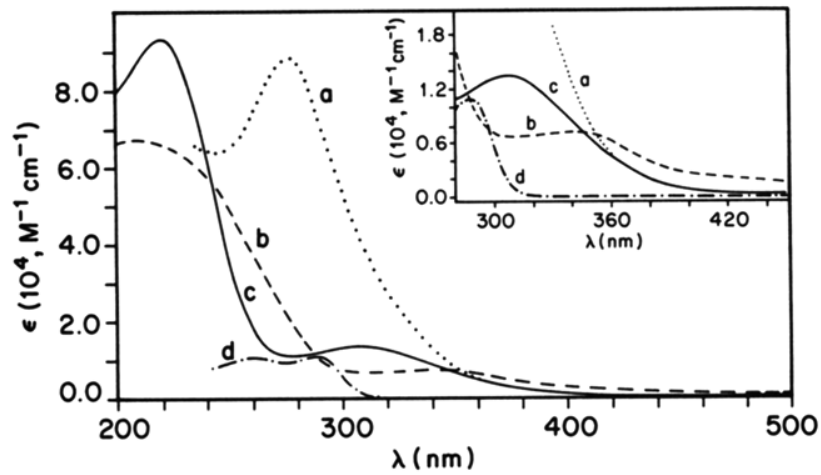

Figure 2. Absorption spectra of hexanuclear complexes in solution: (a) $\mathrm{Ag}_{6}(\mathrm{dtc})_{6}(3)$ in dichloromethane; (b) $\mathrm{Cu}_{6}(\mathrm{mtc})_{6}(1)$ in acetonitrile; (c) $\mathrm{Ag}_{6}(\mathrm{mtc})_{6}(2)$ in acetonitrile. Curve $\mathrm{d}$ is the spectrum for $\mathrm{Na}$ (dtc) in dichloromethane. The inset shows an expansion of the longer wavelength region of these spectra.

transient digitizer (1 and 3) or a Le Croy 9400 Dual 125-MHz digital oscilloscope (2). The Tektronix 7912AD transient digitizer was equipped with a 7B90P programmable time base and a 7A13 differential comparator amplifier. The signal-averaged data $(64$ shots per 512 point array for 1 and 16 shots for 3) were processed using a Zenith ZF-158-42 PC. Data were analyzed by exponential curve fitting. Data for 2 (16 shots per 512 point array) were evaluated manually by a plot of $\ln$ (intensity) versus time. Samples for lifetime measurements were prepared in the same manner as those for emission spectra. Unless otherwise noted, lifetime measurements were reproducible to within $\pm 10 \%$.

High-resolution powder diffraction data were collected for each sample with a Scintag PadX automated powder X-ray diffractometer (Model XPH-105) using $\mathrm{Cu} \mathrm{K} \alpha$ radiation.

\section{Results}

Absorption and Diffuse Reflectance Spectra. The absorption spectra of solution samples of 1-3 and the diffuse reflectance spectra of the solids of the same materials are summarized in Table I. Examples of the solution spectra are shown in Figure 2. These compounds display strong absorptions in the UV region, which appear to be ligand-localized transitions, shifted to somewhat lower energy, plus much weaker bands or shoulders at longer wavelengths. The spectral patterns for the two monothiocarbamate clusters 1 and 2 were similar, with the longer wavelength absorption appearing as a peak at $\sim 340 \mathrm{~nm}$ with a shoulder at $\sim 430$ $\mathrm{nm}$ for $\mathrm{Cu}_{6}(\mathrm{mtc})_{6}$ and as a peak at $\sim 310 \mathrm{~nm}$ and shoulder at $\sim 360 \mathrm{~nm}$ for $\mathrm{Ag}_{6}(\mathrm{mtc})_{6}$. These bands were relatively insensitive to solvent but did shift modestly to higher energy in the more polar media. Diffuse reflectance spectra of the respective solids demonstrated the transitions at nearly the same wavelengths, although
Table I. Solution Absorption and Solid Diffuse Reflectance Data for $\mathrm{Cu}_{6}(\mathrm{mtc})_{6}(1), \mathrm{Ag}_{6}(\mathrm{mtc})_{6}(2)$, and $\mathrm{Ag}_{6}(\mathrm{dtc})_{6}(3)\left(\mathrm{mtc}^{-}=\right.$

di- $n$-propylmonothiocarbamate, $\mathrm{dtc}^{-}=\mathrm{di}-\boldsymbol{n}$-propyldithiocarbamate)

\begin{tabular}{|c|c|c|}
\hline compd & solvent & $\lambda_{\max }^{\mathrm{em} a}(\epsilon)^{b}$ \\
\hline$\overline{\mathrm{Cu}_{6}(\mathrm{mtc})_{6}}$ & $\begin{array}{l}\text { toluene } \\
\mathrm{CH}_{3} \mathrm{CN} \\
\mathrm{CH}_{2} \mathrm{Cl}_{2} \\
\mathrm{CHCl}_{3} \\
\text { ethanol } \\
\text { solidc }\end{array}$ & $\begin{array}{l}342 \text { (p, } 8610), 430(\mathrm{sh}, 1820) \\
206(\mathrm{p}, 67000), 340(\mathrm{p}, 7190), 430(\mathrm{sh}, 1640) \\
340 \text { (p, } 7790), 430(\mathrm{sh}, 1700) \\
336(\mathrm{p}, 7800), 430(\mathrm{sh}, 1420) \\
336 \text { (p, } 7590), 430(\mathrm{sh}, 1620) \\
246 \text { (p), } 346 \text { (p), } 410(\mathrm{sh})\end{array}$ \\
\hline $\mathrm{Ag}_{6}(\mathrm{mtc})_{6}$ & $\begin{array}{l}\text { toluene } \\
\mathrm{CH}_{3} \mathrm{CN} \\
\mathrm{CH}_{2} \mathrm{Cl}_{2} \\
\mathrm{CHCl}_{3} \\
\text { ethanol } \\
\text { solid }^{c}\end{array}$ & $\begin{array}{l}312(\mathrm{p}, 16100), 360(\mathrm{sh}) \\
220(\mathrm{p}, 93600), 308(\mathrm{p}, 13800), 360(\mathrm{sh}) \\
310(\mathrm{p}, 13700), 360(\mathrm{sh}) \\
306(\mathrm{p}, 13500), 360(\mathrm{sh}) \\
220(\mathrm{p}, 93300), 304(\mathrm{p}, 13100), 360(\mathrm{sh}) \\
238(\mathrm{p}), 308(\mathrm{p}), 360(\mathrm{p})\end{array}$ \\
\hline $\begin{array}{l}\mathrm{Na}(\mathrm{mtc}) \\
\mathrm{Ag}_{6}(\mathrm{dtc})_{6}\end{array}$ & $\begin{array}{l}\mathrm{H}_{2} \mathrm{O} \\
\text { toluene } \\
\mathrm{CH}_{2} \mathrm{Cl}_{2} \\
\text { solid }^{c}\end{array}$ & $\begin{array}{l}<200 \\
336(\mathrm{sh}, 16600) \\
276(\mathrm{p}, 88500), 330(\mathrm{sh}) \\
286(\mathrm{p}), 339(\mathrm{p})\end{array}$ \\
\hline $\mathrm{Na}(\mathrm{dtc})$ & $\mathrm{CH}_{2} \mathrm{Cl}_{2}$ & $260(\mathrm{p}, 10800), 291(\mathrm{p}, 10600)$ \\
\hline
\end{tabular}

${ }^{a}$ Wavelength in $\mathrm{nm} ; \mathrm{p}=$ peak, sh $=$ shoulder. ${ }^{b}$ Extinction coefficient in $\mathbf{M}^{-1} \mathrm{~cm}^{-1}$. ${ }^{c}$ Diffuse reflectance spectra.

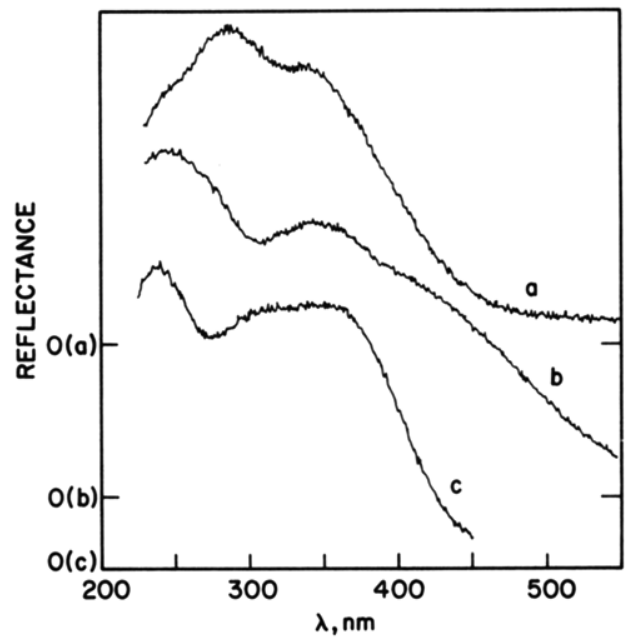

Figure 3. Diffuse reflectance spectra of hexanuclear complexes as solids: (a) $\mathrm{Ag}_{6}$ (dtc) $)_{6}$; (b) $\mathrm{Cu}_{6}(\mathrm{mtc})_{6}$; (c) $\mathrm{Ag}_{6}$ (mtc) $)_{6}$ Zero baselines for (a)-(c) are marked on the ordinate in each case.

the shoulders appeared in the DR spectra as peaks for both 1 and 2 (Figure 3).

The solution absorption spectra of the dithiocarbamate complex $\mathrm{Ag}_{6}(\mathrm{dtc})_{6}$ in different solvents show only a broad shoulder at $\sim 336$ $\mathrm{nm}$ in the near-UV region (Figure 2), although the absorption tails to much longer wavelength. However, this band appears clearly as a peak at $339 \mathrm{~nm}$ in the DR spectrum of solid 3 (Figure 3 ). Attempts to record the spectrum of 3 in acetonitrile or ethanol were unsuccessful owing to low solubility.

Emission Spectra and Lifetimes. Emission spectra and lifetime data are summarized in Tables II and III. The hexanuclear copper(I) cluster 1 exhibits a bright red emission at room temperature, both in toluene solution $\left(\lambda_{\max }^{\mathrm{em}}=725 \mathrm{~nm}\right)$ and as a solid $\left(\lambda_{\max }^{\mathrm{em}}=706 \mathrm{~nm}\right)$. The toluene solution-phase emission spectra of 1 at 294 and $77 \mathrm{~K}$ are shown in Figure 4. Lowering the temperature leads to a narrowing of the emission band, as is typically seen $\left(\Delta \nu_{1 / 2}=\right.$ full width at half-height $=2.7 \times 10^{3} \mathrm{~cm}^{-1}$ at $294 \mathrm{~K}$ and $1.7 \times 10^{3} \mathrm{~cm}^{-1}$ at $77 \mathrm{~K}$ ); however, this is accompanied by an atypical red shift of $\lambda_{\max }^{\mathrm{em}}$ to $762 \mathrm{~nm}$. Both at room temperature and at $77 \mathrm{~K}$ the emission spectrum proved to be independent of the excitation wavelength $\lambda_{\text {exc }}$. Exponential decay was observed at both temperatures with the respective measured lifetimes in toluene being 0.97 and $19.9 \mu \mathrm{s}$. The emission properties of $\mathbf{1}$ in ethanol solution and as a solid were comparable (Tables II and III).

The hexanuclear silver(I) complexes 2 and 3 were found to emit only at $77 \mathrm{~K}$. The bright, unstructured orange emission from the 
Table II. Emission and Excitation Data for $\mathrm{Cu}_{6}(\mathrm{mtc})_{6}(\mathbf{1})$, $\mathrm{Ag}_{6}(\mathrm{mtc})_{6}(2)$, and $\mathrm{Ag}_{6}(\mathrm{dtc})_{6}$ (3)

\begin{tabular}{|c|c|c|c|c|c|c|}
\hline compd & $T^{a}$ & medium & $\lambda_{\max }^{e m b}$ & $\Delta \nu_{1 / 2^{c}}$ & $\lambda_{\max }^{\operatorname{exx}}$ & $\Delta E^{e}$ \\
\hline \multirow[t]{5}{*}{$\mathrm{Cu}_{6}(\mathrm{mtc})_{6}$} & 294 & $\begin{array}{l}\text { solid } \\
\text { toluene }\end{array}$ & $\begin{array}{l}706 \\
725\end{array}$ & $\begin{array}{l}2.7 \\
2.7\end{array}$ & $\begin{array}{l}367-437 \\
351 \text { (p) } \\
425(\mathrm{sh})\end{array}$ & 8.7 \\
\hline & & ethanol & 727 & 2.7 & $\begin{array}{l}351 \text { (p) } \\
427(\mathrm{sh})\end{array}$ & 9.7 \\
\hline & 77 & solid & 767 & 1.6 & $347-475$ & 8.0 \\
\hline & & toluene & 762 & 1.7 & $\begin{array}{l}357(p) \\
430(p)\end{array}$ & 10.1 \\
\hline & & ethanol & 762 & 1.7 & $\begin{array}{l}356(p) \\
429(p)\end{array}$ & 10.2 \\
\hline \multirow[t]{3}{*}{$\mathrm{Ag}_{6}(\mathrm{mtc})_{6}$} & 77 & solid & 644 & 3.1 & $\begin{array}{l}360(p) \\
390(p)\end{array}$ & 10.1 \\
\hline & & toluene & 607 & 3.2 & $\begin{array}{l}325(p) \\
359(p)\end{array}$ & 11.4 \\
\hline & & ethanol & 596 & 3.6 & $\begin{array}{l}324(p) \\
360(\mathrm{sh})\end{array}$ & 11.0 \\
\hline \multirow[t]{5}{*}{$\mathrm{Ag}_{6}(\mathrm{dtc})_{6}$} & 77 & solid & 545 & 1.8 & $\begin{array}{l}367(\mathrm{sh}) \\
430(\mathrm{p}) \\
455(\mathrm{p})\end{array}$ & $\begin{array}{l}4.9 \\
3.6\end{array}$ \\
\hline & & toluene & 550 & 2.4 & $359(\mathrm{sh})$ & \\
\hline & & & & & $431(p)$ & 5.0 \\
\hline & & $\mathrm{CH}_{2} \mathrm{Cl}_{2}$ & 547 & 2.0 & $\begin{array}{l}355 \text { (sh) } \\
425(\mathrm{p})\end{array}$ & 5.2 \\
\hline & & ethanol $/ \mathrm{CH}_{2} \mathrm{Cl}_{2}$ & 546 & 2.0 & $\begin{array}{l}353(\mathrm{sh}) \\
421 \text { (p) }\end{array}$ & 5.4 \\
\hline
\end{tabular}

${ }^{a}$ Temperature in K. ${ }^{b}$ (Uncorrected) emission maximum in nm (excitation wavelength $=\lambda^{e x}$ ). ${ }^{c}$ Full width at half-height of the emission band in $10^{3} \mathrm{~cm}^{-1}$. ${ }^{d}$ Excitation maxima in $\mathrm{nm}$ monitored at $\lambda_{\max }^{\mathrm{em}} ; \mathrm{p}=$ peak, sh $=$ shoulder. 'Energy difference (in $10^{3} \mathrm{~cm}^{-1}$ ) between emission maxima and lowest excitation maximum.

Table III. Emission Lifetimes of $\mathrm{Cu}_{6}(\mathrm{mtc})_{6}(1), \mathrm{Ag}_{6}(\mathrm{mtc})_{6}(2)$, and $\mathrm{Ag}_{6}(\mathrm{dtc})_{6}$ (3)

\begin{tabular}{|c|c|c|c|}
\hline compd & $T^{\alpha}$ & medium & $\tau^{b}$ \\
\hline $\mathrm{Cu}_{6}(\mathrm{mtc})_{6}$ & 294 & $\begin{array}{l}\text { solid } \\
\text { toluene } \\
\text { ethanol } \\
\text { solid } \\
\text { toluene } \\
\text { ethanol }\end{array}$ & $\begin{array}{l}0.99 \\
0.97 \\
0.78 \\
14.0 \\
19.9 \\
18.6\end{array}$ \\
\hline $\mathrm{Ag}_{6}(\mathrm{mtc})_{6}$ & 77 & $\begin{array}{l}\text { solidc }^{c} \\
\text { toluene } \\
\text { ethanol }\end{array}$ & $\begin{array}{l}<83,>109^{c} \\
131 \\
156\end{array}$ \\
\hline $\mathrm{Ag}_{6}(\mathrm{dtc})_{6}$ & 77 & $\begin{array}{l}\text { solid } \\
\text { toluene } \\
\mathrm{CH}_{2} \mathrm{Cl}_{2} \\
\mathrm{EtOH} / \mathrm{CH}_{2} \mathrm{Cl}_{2}\end{array}$ & $\begin{array}{l}8.4 \\
21.3 \\
13.8 \\
12.9\end{array}$ \\
\hline
\end{tabular}

${ }^{a}$ Temperature in $\mathrm{K} .{ }^{b} \tau$ in $\mu \mathrm{s}$; monitored at $\lambda_{\max }^{\mathrm{em}}$ unless noted; experimental uncertainties were $\pm 10 \%$. 'Biexponential decay.

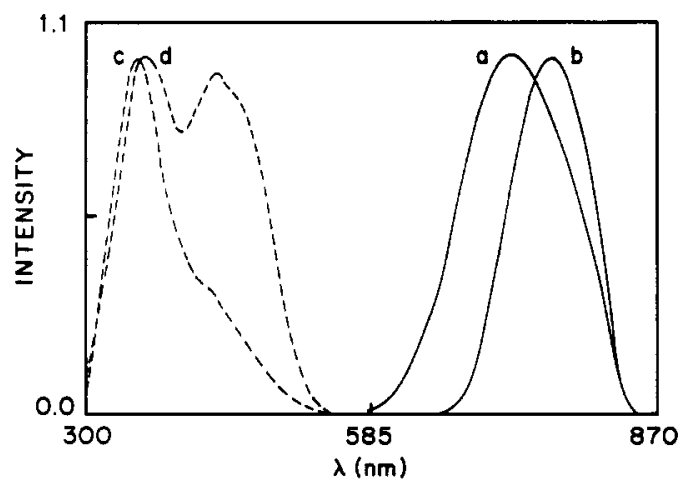

Figure 4. Emission spectra of $\mathrm{Cu}_{6}(\mathrm{mtc})_{6}$ (1) in toluene at (a) $294 \mathrm{~K}$ and (b) $77 \mathrm{~K}\left(\lambda^{\mathrm{ex}}=430 \mathrm{~nm}\right)$ and excitation spectra of 1 in toluene at (c) 294 $\mathrm{K}$ and (d) $77 \mathrm{~K}$, monitored at $\lambda_{\max }^{\mathrm{em}}$. Intensities were normalized for comparison.

monothiocarbamate cluster 2 both as the solid $\left(\lambda_{\max }^{\mathrm{em}}=644 \mathrm{~nm}\right)$ and in toluene solution $\left(\lambda_{\max }^{\text {em }}=607 \mathrm{~nm}\right.$. Figure 5$)$ appears at shorter wavelength than for the copper(I) analogue 1 under the

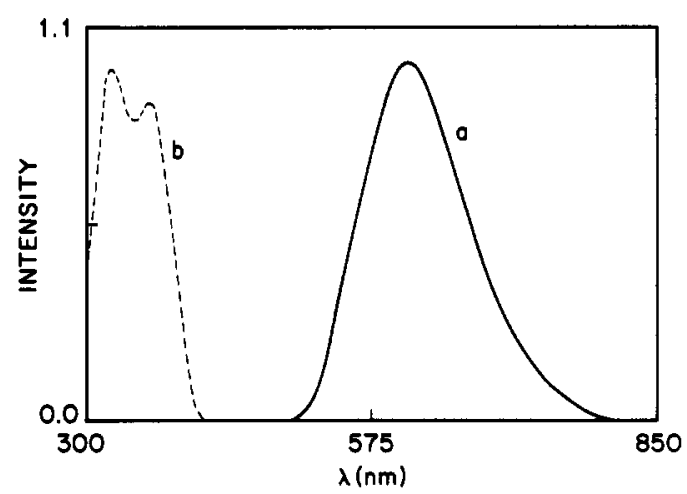

Figure 5. (a) Emission spectrum of $\mathbf{A g}_{6}(\mathrm{mtc})_{6}(2)$ in toluene solution at $77 \mathrm{~K}\left(\lambda^{\mathrm{ex}}=360 \mathrm{~nm}\right)$. (b) Excitation spectrum of 2 in toluene at $77 \mathrm{~K}$ monitored at $\lambda_{\max }^{\mathrm{em}}$. Intensities were normalized for comparison.

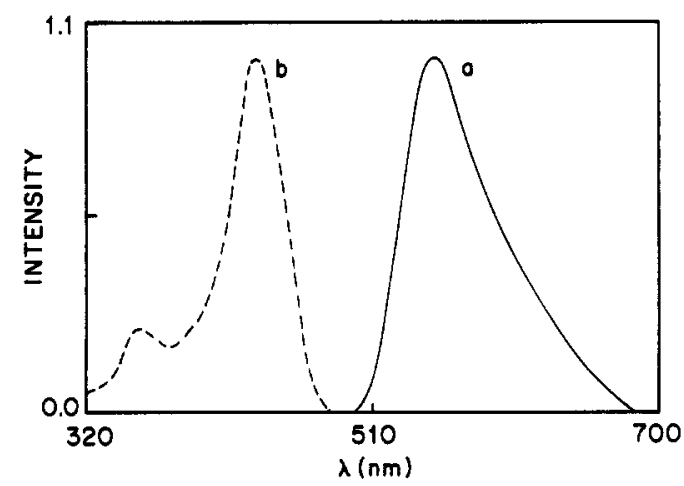

Figure 6. (a) Emission spectrum of the dithiocarbamato cluster $\mathrm{Ag}_{6}(\mathrm{dtc})_{6}$ (3) in $77 \mathrm{~K}$ toluene $\left(\lambda^{\mathrm{ex}}=430 \mathrm{~nm}\right)$. (b) Excitation spectrum of 3 in toluene at $77 \mathrm{~K}$, monitored at $\lambda_{\max }^{\mathrm{em}}$. Intensities were normalized for comparison.

same conditions. The bright green emission from the dithiocarbamato cluster $\left(\mathrm{Ag}_{6}(\mathrm{dtc})_{6}\right.$ occurs at even higher energy with $\lambda_{\max }^{\mathrm{em}}$ values of 545 and $550 \mathrm{~nm}$ (Figure 6) as a solid and in a toluene solution, respectively. For both clusters, the emission spectra were independent of the excitation wavelength and showed only modest shifts to a shorter $\lambda_{\max }^{\mathrm{em}}$ when ethanol was used as the solvent instead of toluene. Lifetime measurements showed the emission from solid 2 to have a lifetime of $\sim 100 \mu$ s but to be nonexponential, while single-exponential decays were observed in ethanol and toluene solutions. Notably, these were nearly an order of magnitude longer (131 \pm 10 and $156 \pm 12 \mu \mathrm{s}$, respectively) than the measured lifetimes of the $\mathrm{Cu}(\mathrm{I})$ analogue 1 under similar conditions (see above) or of the dithiocarbamate complex 3, which gave lifetimes of $8.4 \mu$ s (solid), $21.3 \mu$ s (toluene solution), and $12.9 \mu \mathrm{s}$ (ethanol/dichloromethane solution). Bandwidths and other relevant photophysical data are summarized in Table II.

Excitation Spectra. The excitation spectra for the emissions from toluene solutions of 1-3 (monitoring at $\lambda_{\max }^{\mathrm{em}}$ in each case) are displayed in Figures $4-6$, and the $\lambda_{\max }^{\mathrm{ex}}$ values determined in other media are summarized in Table II. In each case, the excitation spectra displayed two maxima. For the $\mathrm{Cu}_{6}(\mathrm{mtc})_{6}$ in 77 $K$ toluene, the $\lambda_{\max }^{\text {ex }}$ values were 357 and $430 \mathrm{~nm}$, shifted only slightly from those seen in $294 \mathrm{~K}$ solution ( 351 and $425 \mathrm{~nm}(\mathrm{sh})$ ), and these match approximately the $\lambda_{\max }^{\text {abs }}$ values ( 342 and $430 \mathrm{~nm}$ (sh)) seen in the $294 \mathrm{~K}$ toluene solution absorption spectra of 1 . Similarly, the excitation maxima for $\mathrm{Ag}_{6}(\mathrm{mtc})_{6}$ in $77 \mathrm{~K}$ toluene solution occur at wavelengths ( 325 and $360 \mathrm{~nm})$ approximating the $\lambda_{\max }^{\mathrm{abs}}$ of $294 \mathrm{~K}$ toluene solutions ( 312 and $360 \mathrm{~nm}$ ). However, the same cannot be claimed for the $77 \mathrm{~K}$ toluene solution of the (dithiocarbamato)silver(I) cluster, the excitation spectrum of which displayed a $\lambda_{\max }^{\text {ex }}$ at $431 \mathrm{~nm}$, a wavelength for which neither the solution absorption spectra nor the solid diffuse reflectance spectrum (which generally is more sensitive to low energy, forbidden transitions) indicated a transition. The excitation spectra of 3 did indicate a weaker $\lambda_{\max }^{\mathrm{ex}}$ at $\sim 350 \mathrm{~nm}$, which does correspond approximately to the lowest energy shoulder in the ab- 
sorption and diffuse reflectance spectra (Table I). Notably, the Stokes shift from the lowest energy excitation band maximum to the emission band maximum gives a $\Delta E$ of about $10^{4} \mathrm{~cm}^{-1}$ for the two monothiocarbamate clusters, but the higher energy of the emission and the lower energy excitation maximum makes the Stokes shift for the dithiocarbamate complex 3 much smaller.

\section{Discussion}

The following features should be considered in examining the photophysical properties of the $\left(\mathrm{M}^{\mathrm{I}}\right)_{6}$ clusters. First, for each complex, the absorption spectrum shows a lowest energy shoulder or peak in the near-UV region at wavelengths longer than those of the free-ligand absorption bands. ${ }^{17}$ These transitions, which are also prominent in the diffuse reflectance spectra of the solids, follow the energy order $\mathrm{Ag}_{6}(\mathrm{dtc})_{6}>\mathrm{Ag}_{6}(\mathrm{mtc})_{6}>\mathrm{Cu}_{6}(\mathrm{mtc})_{6}$. Second, at $77 \mathrm{~K}$ each of the clusters displays an unstructured, visible-region emission band, the energy order again following the sequence $\mathrm{Ag}_{6}(\mathrm{dtc})_{6}>\mathrm{Ag}_{6}(\mathrm{mtc})_{6}>\mathrm{Cu}_{6}(\mathrm{mtc})_{6}$. The position of this band is relatively independent of the solvent medium. The $\mathrm{Cu}_{6}$ cluster displays this emission at ambient temperature as well, in contrast to the $\mathrm{Ag}_{6}$ clusters. Third, Stokes shifts from the excitation maxima, especially for the two $\mathrm{mtc}^{-}$complexes, are quite large and suggest significant structural distortion between the emitting and ground states. Fourth, luminescence lifetimes at 77 $\mathrm{K}$ are relatively long $(>1 \mu \mathrm{s})$, implying that the transitions involved are forbidden, most likely the result of emissions from triplet excited states.

Structurally, the metal atoms in the hexameric clusters 1 and 2 form nearly regular octahedra with metal-metal distances (1, $2.70-3.06 \AA ; 2.94-3.28 \AA)^{13,15}$ somewhat larger than in the bulk metals (Cu, $2.56 \AA ; \mathrm{Ag}, 2.88 \AA$ ). ${ }^{18}$ If the comparison is made to van der Waals radii of the metals $(1.40$ and $1.70 \AA$, respectively), ${ }^{19}$ the distances are closer; indeed, the average $\mathbf{A g}-\mathbf{A g}$ distance in $\mathbf{2}$ is somewhat less than the summed van der Waals radii $(3.4 \AA)$. For 3 , the $\left(\mathrm{Ag}^{\mathrm{I}}\right)_{6}$ core is more distorted from a regular octahedron, with a set of six short $(2.91-3.20 \AA)$ and six long (3.85-4.01 $\AA$ ) Ag-Ag edges. ${ }^{14}$ Six of the eight triangular faces of the $\left(M^{\mathrm{I}}\right)_{6}$ octahedral cores are capped by the bidentate ligands with a sulfur atom bridging one $\mathrm{M}-\mathrm{M}$ edge and the oxygen of $\mathrm{mtc}^{-}$or the second sulfur of $\mathrm{dtc}^{-}$terminally bound to the third $\mathbf{M}$ on the face, as illustrated in Figure 1. Cryoscopic and ebullioscopic measurements have verified that the hexameric units of the three compounds are preserved in solution. ${ }^{16}$ This conclusion is supported by the similarities observed here for the emission spectra of each of these cluster compounds in the solid and in solution. Notably, there is a strong qualitative similarity between the absorption and emission spectral features of $1-3$, which suggests that these may be characteristic properties of these $\left(M^{I}\right)_{6}$ clusters.

A detailed interpretation of the complicated electronic structures of these clusters will not be attempted here. However, a qualitative model which accounts for some features in the absorption and emission spectral properties will be developed in the following discussion.

Possible assignments for the excited states relevant to the emissions observed are ones originating from ligand-centered $\pi-\pi^{*}$ (LC) transitions, from metal- (or cluster-) centered $d \rightarrow s$ transitions, or from either metal-to-ligand (MLCT) or ligand-to-metal charge-transfer (LMCT) transitions. Of these, neither the LC nor the MLCT assignment would appear likely. The LC transitions appear to be too high in energy, especially for the $\mathrm{mtc}^{-}$ ligand $\left(\lambda_{\max }^{\mathrm{abs}}<200 \mathrm{~nm}\right)$, to be responsible for either the lowest energy absorptions or the emission bands. The LC absorption bands of other $\mathrm{dtc}^{-}$complexes, e.g., $\mathrm{Zn}(\mathrm{dtc})_{2}$, have energies close to those of the free anion; ${ }^{17}$ furthermore, it is notable that the free ligands as sodium salts do not display any visible-range emissions. MLCT excited states have been identified as important in the

(17) Octavec, D.; Stefanec, J.; Siles, B.; Konecny, V.; Garaj, J. Collect Czech. Chem. Commun. 1979, 44, 2487-2493 and references therein.

(18) Wells, A. F. Structural Inorganic Chemistry, 5th ed.; Clarendon Press: Oxford, U.K., 1984.

(19) Bondi, A. J. Chem. Phys. 1964, 41, 3199.

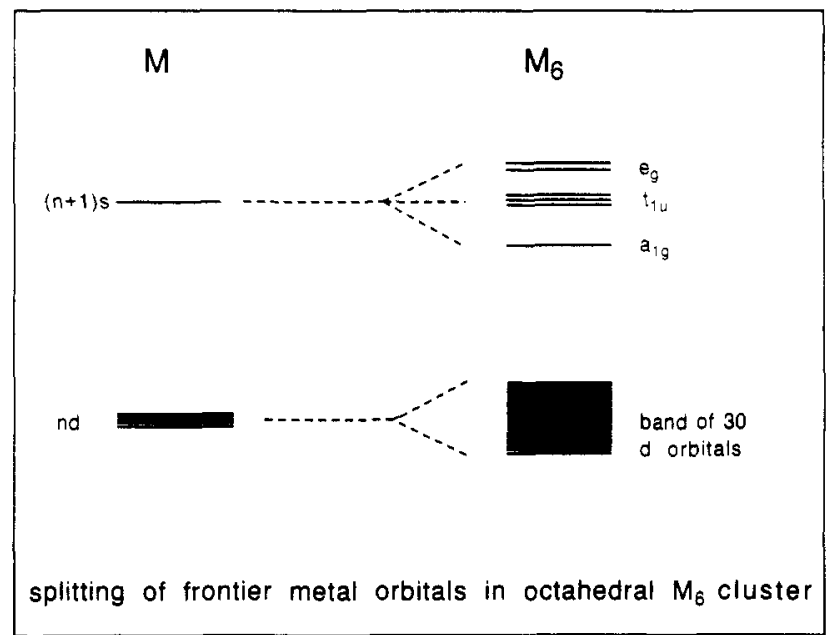

Figure 7. Metal orbitals of the $\mathrm{M}_{6}$ octahedron (diagram adapted from ref 30 ).

photophysical properties of the copper(I) complexes of easily reducible ligands such as phenanthroline, ${ }^{20}$ but such an assignment does not seem reasonable for the mono- and dithiolato ligands, especially in light of the relevant bands for the $\mathrm{Cu}(\mathrm{I})$ and $\mathrm{Ag}(\mathrm{I})$ complexes having similar energies. Generally, $\mathrm{Cu}(\mathrm{I})$ is much more easily oxidized, given the higher energy of the $\mathrm{Cu} 3 \mathrm{~d}$ orbitals relative to those of the $\mathrm{Ag} 4 \mathrm{~d}$ orbitals. ${ }^{21}$ Furthermore, the $\pi^{*}$ orbitals of $\mathrm{mtc}^{-}$and $\mathrm{dtc}^{-}$are too high in energy to be realistically expected to act as acceptor orbitals for low-lying MLCT transitions.

The above considerations leave the LMCT and metal-centered $\mathrm{d} \rightarrow \mathrm{s}$ transitions as the most likely assignments. Since the electron affinities of the free $\mathrm{Cu}^{+}$and $\mathrm{Ag}^{+}$ions are comparable, ${ }^{22}$ to a first approximation LMCT transitions of the $\mathrm{Cu}(\mathrm{I})$ and $\mathrm{Ag}(\mathrm{I})$ complexes of similar ligands should have comparable energies although, for the hexanuclear clusters, the molecular orbitals would certainly be dependent on the extent of mixing due to metal-metal and metal-ligand covalent interactions. The optical electronegativities of dithiocarbamato ligands are relatively small $(2.7),{ }^{23}$ just higher than that of iodide (2.5). ${ }^{24}$ Given that the thiocarbamate complexes of more oxidizing metal ions such as $\mathrm{Cu}$ (II) or $\mathrm{Ag}$ (II) are strongly colored owing to LMCT absorption bands in the visible region, ${ }^{23,25}$ it is reasonable to speculate that the analogous bands for the $\mathrm{Cu}(\mathrm{I})$ and $\mathrm{Ag}(\mathrm{I})$ clusters would appear in the near-ultraviolet region of the spectrum.

Alternatively, since $\mathrm{d} \rightarrow \mathrm{s}$ transitions of the free ions $\mathrm{Cu}^{+}(\mathrm{g})$ and $\mathrm{Ag}^{+}(\mathrm{g})$ occur at relatively low energies $\left(21.93 \times 10^{3}\right.$ and 26.26 $\times 10^{3} \mathrm{~cm}^{-1}$, respectively, for the lowest energy spin-forbidden and spin-allowed transitions of the former, $39.16 \times 10^{3}$ and $46.05 \times$ $10^{4} \mathrm{~cm}^{-1}$ for the analogous transitions of the latter), ${ }^{21 \mathrm{~b}, \mathrm{c}} \mathrm{d} \rightarrow \mathrm{s}$ states would also appear to be reasonable candidates for low-lying excited states among the $\left(M^{1}\right)_{6}$ clusters. The appearance of both the longest wavelength absorption band and the emission band for the $\mathrm{Cu}(\mathrm{I})-\mathrm{mtc}$ cluster 1 at a somewhat lower energy than for

(20) Ichinaga, A. K.; Kirchhoff, J. R.; McMillin, D. R.; Dietrich-Buchecker, C. O.; Marnot, P. A.; Sauvage, J.-P. Inorg. Chem. 1987, 26, 4290-4292 and references therein.

(21) (a) The ionization energy of $\mathrm{Ag}^{+}(\mathrm{g})\left(173.30 \times 10^{3} \mathrm{~cm}^{-1}\right)^{21 \mathrm{~b}}$ is nearly $10^{4} \mathrm{~cm}^{-1}$ larger than that for $\mathrm{Cu}^{+}(\mathrm{g})\left(163.67 \times 10^{3} \mathrm{~cm}^{-1}\right){ }^{21 \mathrm{c}}$ (b) Moore, C. E. Natl. Stand. Ref. Data Ser. (U.S., Natl. Bur. Stand.) 1971, NSRDS-NBS 35, 51. (c) Moore, C. E. Natl. Stand. Ref. Data Ser. (U.S., Natl. Bur. Stand.) 1971, NSRDS-NBS 35, 116.

(22) (a) The ionization energies of atomic $\mathrm{Cu}$ and $\mathrm{Ag}$ are $6.232 \times 10^{4}$ and $6.111 \times 10^{4} \mathrm{~cm}^{-1}$, respectively. ${ }^{22 \mathrm{~b}}$ (b) CRC Handbook of Chemistry and Physics, 71st ed.; Lide, D. R., Ed.; CRC Press: Boston, MA, 1990; pp $10-210$.

(23) Jørgensen, C. K. Inorganic Complexes; Academic Press: London, 1963; pp 136-137.

(24) Lever, A. B. P. Inorganic Electronic Spectroscopy, 2nd ed.; Elsevier: Amsterdam, 1984; p 221.

(25) Kita, H.; Migake, S.; Tanaka, K.; Tanaka, T. Bull. Chem. Soc. Jpn. $1979,52,3532-3538$. 
the $\mathrm{Ag}(\mathrm{I})$ analogue 2 would be consistent with the ordering of the $\mathrm{d} \rightarrow \mathrm{s}$ energies of the mononuclear free ions (above), but the differences are much smaller. Ligand coordination would be expected to raise s-orbital energies substantially, but the effect of metal-metal interactions in the $\left(\mathbf{M}^{\mathrm{I}}\right)_{6}$ octahedra would lead to substantial splitting of the $d$ and (especially s) orbitals in a manner which may lead to marked effects on the expected molecular orbital energies. A diagram representing the resulting cluster metal MO's is displayed in Figure 7 and illustrates the stabilization of the lowest energy unfilled s orbital and corresponding destabilization of the highest energy filled d orbital. It is likely that the metal-metal interactions in the silver clusters are substantially greater than in the respective copper cluster because, relative to the sums of their respective van der Waals radii, the $\mathbf{A g}-\mathbf{A g}$ distances, especially in 2 but also in 3 , are significantly shorter than the $\mathrm{Cu}-\mathrm{Cu}$ distance in 1 . This enhanced interaction should decrease the $d \rightarrow s$ separation accordingly.

Earlier studies from these two laboratories ${ }^{2,3}$ have identified strong, low-energy emission bands in the luminescence spectra of the $\mathrm{Cu}(\mathrm{I})$ cluster $\mathrm{Cu}_{4} \mathrm{I}_{4}(\mathrm{py})_{4}(4)$ and a series of related $\mathrm{Cu}_{4} \mathrm{I}_{4} \mathrm{~L}_{4}$ analogues where $\mathrm{L}$ is either a saturated or aromatic amine. Recent $a b$ initio calculations ${ }^{26}$ have concluded that the emitting excited state can be viewed to be of mixed character consisting of roughly equal parts of iodide to copper charge transfer (XMCT, $X=I$ ) and metal-centered $\mathrm{d} \rightarrow \mathrm{s}$ contributions, the energies markedly influenced by the metal-metal interactions in the excited state. Blass $e^{27}$ has reached a similar conclusion. The idea of mixed $d$ $\rightarrow \mathrm{s} / \mathrm{XMCT}$ character of electronic transitions was advanced some years ago by Jørgensen ${ }^{28}$ to explain the absorption spectra of $\mathrm{Cu}(\mathrm{I})$ and $\mathbf{A g}(\mathrm{I})$ halide salts. For example, when $\mathrm{Ag}^{+}$is doped into alkali metal halides $\left(\mathrm{X}^{-}\right)$, the longest wavelength " $\mathrm{d} \rightarrow \mathrm{s}$ " transition follows the energy order $\mathrm{Cl}^{-}>\mathrm{Br}^{-}>\mathrm{I}^{-}$. The iodide salts show the largest shift to lower energy due to greater mixing of the metal d orbitals with the halide p orbitals and, hence, a greater LMCT contribution to the transition.

Also relevant to the present discussion is a self-consistent charge and configuration MO investigation ${ }^{29}$ of $\mathrm{Cu}(\mathrm{I})$ clusters of the type

(26) (a) Vitale, M.; Palke, W. E.; Ford, P. C. Submitted for publication. (b) Kyle, K. R.; Palke, W. E.; Ford, P. C. Coord. Chem. Rev. 1990, 97, 35-46.

(27) Blasse, G. Struct. Bonding 1991, 76, 153-187.

(28) Jørgensen, C. K. Oxidation Numbers and Oxidation States; Springer Verlag: New York, $1969 ; \mathrm{p} 128$.

(29) Avdeef, A.; Fackler, J. P., Jr. Inorg. Chem. 1978, 17, 2182-2187. having a $\mathrm{Cu}_{8} \mathrm{~S}_{12}{ }^{4-}$ core with the eight coppers in a cubane configuration with $\mathrm{Cu}-\mathrm{Cu}$ distances of $2.83 \AA$ and the sulfurs coming from bidentate ions such as 1,1-dicyanoethylene-2,2-dithiolate. This study concluded that the HOMO's are largely sulfur in character while the LUMO is primarily copper $4 s$ and $4 \mathrm{p}$ and sulfur $3 p$ orbitals. These results would imply that the HOMO's for the octahedral clusters described in the present case are also largely ligand in character. However, the ab initio calculations described for the $\mathrm{Cu}(\mathrm{I})$ tetrahedra ${ }^{26 a}$ clearly indicate considerable ground-state charge delocalization from ligand anions to the metal core and much less than a full electron transfer from ligand to metal in the lowest energy excited state. Thus, in such a case, viewing the ES conveniently as simply the product of a one-electron HOMO $\rightarrow$ LUMO transition may present an incomplete picture of the changes wrought by the electronic excitation.

In the context of the calculations described above for $\mathrm{Cu}_{4} \mathrm{I}_{4}(\mathrm{py})_{4}$, a "cluster-centered" (CC) state with both $\mathrm{d} \rightarrow \mathrm{s}$ and LMCT character would appear to be an accurate, although qualitative, description of the luminactive excited states of 1-3. The $a_{1 g}$ lowest unoccupied MO of the $\left(\mathrm{M}^{\mathrm{I}}\right)_{6}$ octahedra (Figure 7 ) would be largely metal s orbital in character and would be a bonding MO with respect to the metal-metal interactions. Therefore, a $\mathrm{d} \rightarrow$ $s$ transition, a LMCT transition, or the presumed CC transition of mixed character would lead to population of this orbital with a resulting contraction of the $\left(\mathrm{M}^{\mathrm{I}}\right)_{6}$ octahedron. Such a distortion would be one factor accounting for the large Stokes shift from the excitation maxima to the emission maxima of the two monothiocarcarbamate complexes 1 and 2 . We do not have as ready an explanation for the smaller, but still substantial, Stokes shift for 3, although it should be noted that, in the ground state for this species, the $\left(\mathbf{M}^{\mathrm{I}}\right)_{6}$ core is already significantly distorted from the nearly regular octahedra which characterize the other two. The relatively long emission lifetimes at $77 \mathrm{~K}$ for 1-3 (Table III) are consistent with those expected for a spin-forbidden transition in such metal complexes. The emitting state is thus concluded to be a triplet CC ES of mixed $d \rightarrow s$ and LMCT character.

Acknowledgment. This research was supported by the Deutsche Forschungsgemeinschaft (Grant Vo 211/9-1) and the U.S. National Science Foundation (Grant CHE 87-22561). F.S. gratefully acknowledges a travel grant from the German Academic Exchange Service (daad). We thank Dr. N. L. Keder of UCSB for her help in recording and interpreting X-ray powder diffraction data.

(30) Mingos, D. M. P. J. Chem. Soc., Dalton Trans. 1976, 1163-1169.

Contribution from the Institute of Chemical Engineering and High Temperature Chemical Processes and Department of Chemical Engineering, University of Patras, P.O. Box 1239, GR-26110 Patras, Greece

\title{
Raman Spectroscopic Studies of Metal-Metal Halide Molten Mixtures: The Mercury-Mercury(II) Halide Systems
}

\author{
G. A. Voyiatzis and G. N. Papatheodorou*
}

Received April 9, 1991

\begin{abstract}
Raman spectra of molten $\mathrm{HgX}_{2}-\mathrm{Hg}(\mathrm{X}=\mathrm{Cl}, \mathrm{Br}, \mathrm{I})$ systems have been obtained at compositions up to $30 \mathrm{~mol} \%$ in $\mathrm{Hg}$ from 550 to $818 \mathrm{~K}$. The dissolution of mercury in mercury halides gives rise to resonance-enhanced Raman bands which were interpreted to account for $\mathrm{Hg}_{2} \mathrm{X}_{2}$ type molecular species formed in all mercury compositions and $\mathrm{Hg}_{3} \mathrm{X}_{2}$ type molecules formed at high mercury mole fractions. Spectra were also obtained from $\mathrm{HgX}_{2}-\mathrm{HgX}_{2}^{\prime}-\mathrm{Hg}(\mathrm{X}=\mathrm{F}, \mathrm{Cl}, \mathrm{Br}, \mathrm{I})$ mixtures and were attributed to mixed mercury(I) (sub)halide molecules $\mathrm{Hg}_{2} \mathrm{XX}^{\prime}$ formed in the melt. The $\mathrm{Hg}_{2} \mathrm{X}_{2}$ and $\mathrm{Hg}_{2} \mathbf{X X}^{\prime}$ molecules possess a linear symmetry, and the $\mathrm{Hg}-\mathrm{Hg}$ stretching frequencies for all 10 molecules were found to be between $\sim 180 \mathrm{~cm}^{-1}\left(\mathrm{Hg}_{2} \mathrm{~F}_{2}\right)$ and $\sim 100 \mathrm{~cm}^{-1}\left(\mathrm{Hg}_{2} \mathrm{I}_{2}\right)$. A linear $\mathrm{Hg}_{3}$ chain is formed in the $\mathrm{Hg}_{3} \mathrm{X}_{2}$ molecules bound to two terminal halides. The formation of $\mathrm{Hg}_{3}$ chains was further confirmed by the Raman spectra of $\mathrm{Hg}_{3}\left(\mathrm{AlCl}_{4}\right)_{2}$ melts. It is suggested that in the melt mixtures intermolecular interactions between $\mathrm{HgX}_{2}$ and $\mathrm{Hg}_{2} \mathrm{X}_{2}$ molecules lead to an alteration of oxidation states which account for a "hopping" like conduction.
\end{abstract}

\section{Introduction}

At elevated temperatures many metals are to some extent soluble in their molten halide salts, forming, in most cases, colored solutions. The basic physical properties and the equilibrium phase diagrams of a large number of metal-metal halide (M-MX $)$ systems were determined in the 1960s, and most of this work was summarized in reviews by Bredig ${ }^{1}$ and Corbett. ${ }^{2}$ Some interesting

(1) Bredig, M. A. In Molten Salt Chemistry; Blander, M., Ed.; Interscience: New York, 1964; p 367-425. 